\title{
Estudo Bibliométrico sobre Planejamento Estratégico, Balanced Scorecard e Sustentabilidade
}

Bibliometric Study on Strategic Planning, Balanced Scorecard and Sustainability

Estudio Bibliométrico sobre Planificación Estratégica,

Balanced Scorecard y Sostenibilidad

Sandra Valéria Gilberti Prenstteter

Mestranda, PUC-Campinas, Brasil sandra.gilberti@uol.com.br

Marcos Ricardo Rosa Georges

Professor Doutor, PUC-Campinas, Brasil.

marcos.georges@puc-campinas.edu.br 


\section{INTRODUÇÃO}

Toda organização possui uma estratégia. Em alguns casos a estratégia é clara, em outros casos a estratégia é intuitiva. No entanto, para que as organizações se tornem cada vez mais competitiva é importante que tenha uma estratégia clara. Para isto, deve-se considerar a importância do Planejamento Estratégico para as organizações e compartilhado com todos os envolvidos.

Kotler (1992) define o planejamento estratégico como uma metodologia gerencial que permite estabelecer a direção a ser seguida pela empresa, visando maior grau de interação com o ambiente. Para Porter (1980), o sucesso para o alcance de uma vantagem competitiva está na escolha de uma estratégia adequada.

Os métodos de planejamento estratégico vêm evoluindo ao longo do tempo e na década de 1990, o Balanced Scorecard (BSC) foi uma grande evolução no campo da estratégia desenvolvido por Kaplan e Norton. O BSC é uma ferramenta de gestão que proporciona à empresa avaliar sua estratégia medida pelas perspectivas: financeira, cliente, processos internos e aprendizado e crescimento.

Nos dias atuais, as empresas estão com o desafio de incluir nas suas estratégias às questões relacionadas a sustentabilidade. Este assunto tem obtido relevância nos últimos anos por questões relacionadas aos acidentes ambientais e ao desafio da sobrevivência da humanidade. A sustentabilidade tem expressado notoriedade e parece ser imperativo, um conceito que não tem mais volta, pois a sociedade está cada vez mais exigente com relação ao uso de práticas sustentáveis. Também se observa a sustentabilidade na preferência do consumidor, no surgimento de leis, que são cada vez mais rigorosas, e no contexto da reputação das organizações que podem ser destruídas quando as mesmas não utilizam. Muitas vezes a sustentabilidade e suas ações são condições essenciais para que essas organizações se mantenham no mercado.

Diante da necessidade de incluir a sustentabilidade no escopo do planejamento estratégico das organizações, o BSC parece ser uma ferramenta que pode contribuir nesta perspectiva.

\section{OBJETIVO}

Nesse contexto, o objetivo deste trabalho é avaliar como a produção acadêmica, mais especificamente as teses e dissertações, têm estudado os assuntos: Planejamento Estratégico, BSC e Sustentabilidade.

São objetivos específicos deste trabalho: conhecer melhor o planejamento estratégico, compreender melhor o BSC, entender melhor o conceito de sustentabilidade e avaliar se é possível utilizar o BSC para planejar, monitorar e controlar a sustentabilidade dentro das estratégias das organizações. 


\section{METODOLOGIA}

Este trabalho se caracteriza como um estudo de caráter exploratório, pois apresenta o interesse em conhecer melhor esse assunto. A pesquisa será apresentada de forma quantitativa e qualitativa. $O$ método delineado é um estudo bibliométrico realizado no Banco de dados de Teses e Dissertações (BDTD). Para realizar a pesquisa foi utilizado as palavras chaves simultaneamente: Planejamento Estratégico, Balanced Scorecard e Sustentabilidade.

Como método de análise dos resultados, tem-se análises baseadas em estatísticas e gráficos estratificados nas seguintes critérios: ano de publicação, tipo de trabalho, instituição de ensino, área de conhecimento, segmento de atuação e metodologia utilizada.

\section{RESULTADOS}

Após análise dos itens disponíveis no Banco de Dados de Teses e Dissertações (BDTD), foram localizados onze trabalhos e dentre estes, selecionados nove que apresentou maior relevância com o objetivo desta pesquisa.

Considerando os resumos dos textos, os seguintes resultados foram produzidos conforme os gráficos e análises descritos a seguir.

Figura 1: Ano de publicação

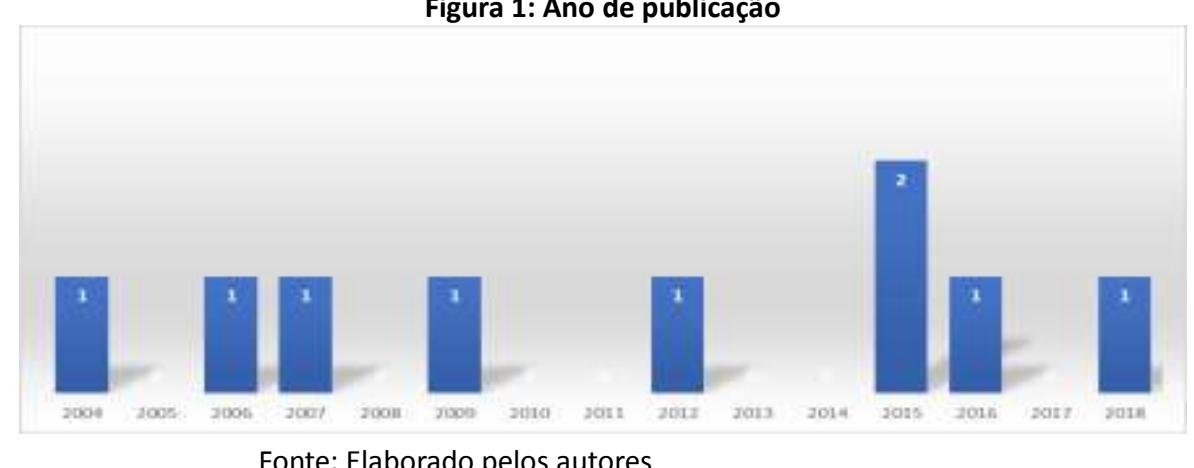

Fonte: Elaborado pelos autores

Referente ao ano de publicação, observa-se por meio da figura 1 que os trabalhos da amostra foram publicados em anos alternados e que não se evidencia uma sequência de publicações do tema, outro aspecto é que não foi encontrado um número expressivo de trabalhos de teses e dissertações sobre os temas. 




Fonte: Elaborado pelos autores

Com relação ao tipo de trabalho, observa-se por meio da figura 2 que foram analisados seis teses e três dissertações publicados sobre os temas.

Figura 3: Instituição de origem



Fonte: Elaborado pelos autores

Quando analisado em quais instituições houve publicação, verificou-se por meio da figura 3 que a Universidade do Sul publicou dois trabalhos, a Universidade de Santa Catarina publicou dois trabalhos, a Universidade do Rio Grande do Sul publicou dois trabalhos, a Universidade Estadual do Oeste do Paraná publicou um trabalho, Universidade La Salle (Canoas) publicou um trabalho e a Universidade Federal do Rio Grande do Norte. Evidencia-se que a região Sul tem $67 \%$ das publicações relacionadas aos temas Planejamento Estratégico, BSC e Sustentabilidade.

Figura 4: Área do conhecimento




Com relação a área de conhecimento, destaca-se por meio da figura 4 que quatro trabalhos estão relacionados a Administração, dois a Engenharia de Produção e Sistemas, um a Educação, um a Estrutura e Qualidade e um a Medicina. Dessa forma, a área da Administração publicou mais trabalhos relacionados ao tema.



Fonte: Elaborado pelos autores

Dos trabalhos analisados por segmento da organização, podemos verificar por meio da figura 5, dois deles foi do terceiro setor, um na área de saneamento, um no setor elétrico, um na área da educação, um na área tecnologia, um na área Química e um apresentado como modelo teórico a ser utilizado.

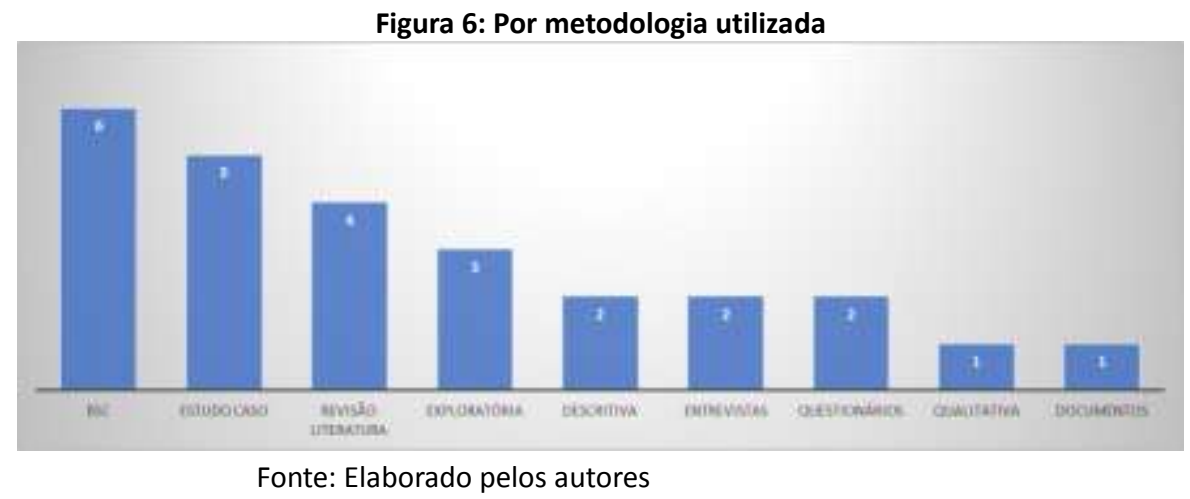

Analisando a metodologia por meio da figura 6, podemos evidenciar que seis dos trabalhos utilizaram BSC, cinco utilizaram estudo de casos, quatro utilizaram revisão de literatura, três utilizaram análise exploratória, dois descritiva, dois entrevistas, dois questionários, um dos trabalhos utilizaram análise qualitativa e um deles utilizou documentos da organização. É importante ressaltar que alguns dos trabalhos utilizaram simultaneamente o conjunto de metodologias como complemento para análise de seus respectivos dados.

\section{CONCLUSÕES}

O presente estudo bibliométrico propôs uma análise quanto ao interesse acadêmico com relação ao tema Planejamento Estratégico, BSC e Sustentabilidade, frente as teses e dissertações produzidas dentro do curso de pós-graduação strictu sensu no Brasil, utilizando as 
produções contidas no Banco de Dados de Teses e Dissertações. Percebe-se que com relação aos três temas simultâneos Planejamento Estratégico, BSC e Sustentabilidade ainda tem poucas produções e merece destaque ao tema as universidades do Sul do Brasil, e os cursos de administração de empresas.

Considerando a importância do planejamento estratégico para as organizações aliado a sustentabilidade deparamos com poucos trabalhos desenvolvidos relacionados aos temas. $\mathrm{E}$ face a relevância desse tema para evolução e clareza para evolução das estratégias das organizações, reforçam a necessidade de mais publicações que vinculem os temas.

\section{REFERÊNCIAS BIBLIOGRÁFICAS}

PORTER, Michael E. Strategy competitive. Techniques for analyzing industries and competitors. New York, 1980.

KOTLER, Philip. Administração de marketing: análise, planejamento, implementação e controle. 2. ed. São Paulo: Atlas, 1992.

KAPLAN, R. S.; NORTON, D. P. A estratégia em ação: Balanced Scorecard. Ed. Campus, 360 p., 1997.

KAPLAN, R. S.; NORTON, D. P. Alinhamento - utilizando o BSC para criar sinergias corporativas. Rio de Janeiro: Alta Books, 2017. 